\title{
A LINGUAGEM CÔMICA DE ARISTÓFANES
}

\section{Gilda Maria Reale Starzynski}

Forçoso é reconhecê-lo: Aristófanes não é um autor muito apreciado e bem compreendido pela maioria dos críticos modernos. Já pelo fato de ter cultivado uma comédia satírica, de mordaz crítica pessoal, sem a menor preocupação de esboçar ou de criar tipos, mas que tinha em mira pessoas e situações reais, para recriálas no mundo da ficção, Aristófanes é estudado mais como político, moralista e até crítico literário do que como um verdadeiro poeta cômico. E, por tudo isso, é muitas vêzes apontado como um au or completamente distante de nosso mundo atual, criador de um cômico rançoso, desinteressante e superado, incapaz de despertar o menor sorriso de um espectador moderno.

Não negamos que é muito difícil defender a universalidade da obra de Aristófanes. Profundamente comprometida com a realidade de seu tempo, a sua comédia só pode ser verdadeiramente entendida e apreciada pelo espectador moderno após haver passado pelo crivo das adaptações. A sua própria estrutura é bem diferen e daquela tradicional, que chegou até nós através do teatro latino ou das comédias de um Molière, por exemplo. Que fazer da "parábase", aquêle momento essencialmente anti-dramático em que o corifeu tirava a máscara e falava diretamente ao público, discursando em nome do poeta, expondo as suas opiniões sôbre ques:ões geralmente sem a menor vinculação com o assunto da peça? E as di iculdades ainda aumentam, se pensarmos que essa ruptura da tensão dramátíca não se dá em qualquer momento $d_{a}$ peça, mas justamente no instante em que a ação parece encaminhar-se para o climax.

Como explicar a sucessão de cenas de pura farsa, logo após a parábase, verdadeiros "sketchs" cômicos em que a tensão se vai dissolvendo gradativamen'e, cada vez de forma mais grosseira, na apresentação de dois ou três quadros em que se vão colher os frutos de um projeto louco e fantástico, que o protagonista pusera em marcha, no prólogo? Como aceitar êsse contraste entre as sutilezas dos primeiros momentos da peça e tal seqüência de palhaçadas, cenas de verdadeira chanchada? (1)

(1) - Não devemos perder de vista que êsses aparentes defeitos estruturais resultam do apêgo aos padrões tradicionais de composição, na chamada comédia ática antiga. 
Se não podemos deixar de reconhecer que há, de fato, uma certa dificuldade de comunicação entre o teatro de Aristófanes e o espectador moderno, nem por isso chegaremos ao extremo de negar qualquer possibilidade de entendimento; ao contrário, somos de opinião que emerge de suas páginas um grande criador de situações cômicas, um poeta que se revela possuidor dêsse dom maravilhoso de fazer rir

Mas haverá possibilidade de um cômico eterno e universal? A rigor, sim, desde que não dependa diretamente da linguagem, quando não exige tradução, porque se cria com gestos, mímica, movimentação. Tal é o caso da "commedia dell'arte", dos filmes de Carlitos, ou ainda das pantomimas de palhaços que podem passar tranquiilamente de um país a outro, através de gerações e gerações. Já não seria o caso, no entanto, das grandes criações de um $\mathrm{Mr}$. Hulot, o perionagem criado pelo gênio de Jacques Tati, pelo menos em sua fase mais recente, pois, apesar de não haver ainda uma dependência direta só da linguagem, já podemos no:ar vestígios de um certo intelectualismo, pouco natural, na medida em que há maior vinculação dos temas e "gags" com a crítica de nossa sociedade de consumo. Quando o cômico se intelectualiza e passa a ser manipulado com palavras e idéias, já é mais difícil de captar; torna-se ugidio, transitório, efêmero.

E é justamente êsse $o$ caso de Aris'ófanes. Na época de sua representação, na Atenas do sec. V a. C., suas peças deviam ter uma fôrça de comunicação extraordinária. Eram espetáculos cheios de côr, movimento, sons, variedade. O côro, representando o mundo não humano das nuvens, dos pássaros, das vespas ou das rãs, por exemplo, dava às peças um colorido todo especial. As máscaras e gistos que se repetiam, as tropelias dos coreutas, ora correndo em magotes, ora dispersando-se na orquestra, investindo con:ra as personagens, trocando impropérios com elas, tudo isso criava situações intensamente cômicas, não só pelo automatismo dos gestos como pelos próprios contrastes que surgiam a cada momento. Os disfarces das personagens, as máccaras ridículas oom que encobriam os rostos, os tradicionais enchimentos e protuberâncias no peito e no traseiro, os sugestivos pedaços de couro que mal e mal apareciam sob as baínhas das túnicas ou se arrastavam indecentemente pelo chão, os cantos, os ritmos das danças que alternavam os passos, do mais intenso patético à farsa mais grotesca e obscena, tudo era motivo de riso e faniasia.

Ora, tudo isso está perdido. Podemos tentar reconstituí-lo vagamente, recorrendo às sugestões do próprio texto, aos achados da arqucologia, à paciente recriação de alguns trajes, de uns parcos gestos e atitudes, a partir de cenas pintadas em vasos, mas o re- 
sultado será sempre fragmen ário, muito aquém do que poderia ter sido a representação num teatro ateniense.

A própria cidade em que se criou e viveu êsse cômico está infi_ nitamente longe de nós, também se perdeu para sempre. A Atenas de Aristófanes poderá ser imaginada, reconstruída em nosso pensamento, mas as suas casas, ruas, vielas e praças continuarão desertas, jamais poderão voltar à vida .

Que restou então dêsse naufrágio? Apenas a linguagem, e, assim mesmo, são inúmeros os problemas que oferece aos que pretendem recriá-la ou estudá-la.

Para começar. devemos distinguir en 're o cômico que a linguagem expressa e aquêle que a linguagem cria. $O$ primeiro admıte tradução de uma língua para outra, ainda que às custas de uma perda de relêvo, já pelo fato de ter de adaptar-se a uma sociedade diferente, nos costumes e sobretudo na associação de idéias, mas - segundo é prà icamente intraduzível, pois a sua essência é a própria estrutura da frase, a escolha dos vocábulos, a tessitura fonética.

Infelizmente para nós, leitores ou tradutores, seja qual fôr a perspectiva em que procuremos captar a linguagem cômica de Aristófanes, sempre estaremos pisando em terreno incerto e escorregadio. Muitas vêzes, detemo-nos em passagens, percebemos a alusão, a paródia, o jôgo de palavras e subentendidos, mas licamos tateando às escuras; apelamos a comentadores antigos, à procura de uma luz que nos ilumine, e continuamos a sentir, de longe, a fragância dêsse cômico, que não conseguimos apreender. E' que a sociedade, os costumes, a própria "gente" que êle retrata estão mortos, nada porderá fazê-los ressuscitar. E, à medida que o poeta vai inventando as situações, vai criando uma linguagem cada vez mais rica, mas dirícil de cap ${ }^{+}$ar porque mais original e expressiva. Trata-se, então, de um autêntico desafio ao tradutor, frustrado, humilhado diante de um dilema: ou se mantém fiel ao texto "ex literis" e, muitas vêzes, acaba matando o cômico, ou então é obrigado a adaptar, recompor, procurar situações paralelas ou correspondentes, ainda que se afaste do original. Mas, se sacrifica a letra, consegue salvar pelo menos o espírito, e ainda cremos ser esta a melhor solução, talvez aquela que o próprio Aristófanes recomendaria. (2) Todavia, pemanecerá sempre aquela frustação de ter conseguido apenas um simulacro, uma imitação pobre em face das riquezas do original.

(2) - A propósito, citamos o testemunho de outro grande poeta cômico, Marivaux, ao c:iticar o trabalho de um tradutor: "E', êle traduziu certo, mas pôs a peça a perder ..." 
Ao tentar recompor os elementos e processos mais característicos da linguagem cômica de Aristófanes, já pelos limites que impusemos à extensão do presente trabalho, fomos obrigados a fazer uma seleção. Assim, deixamos de lado as partes líricas em que há, evidentemente, intenções cômicas mas que poderiam interessar-nos, antes de mais nada, como exemplos de realização de fantasia poética. Também não vamos a'ongar-nos na discussão do emprêgo de onomatopéias, aliterações, rimas, combinações expressivas de sons, o que, além de constituir material suficiente para uma extensa monografia, exigiria a referência constante a textos gregos, problema êsse que procuramos evitar, atendendo a obstáculos de ordem material.

Autor do séc.V a. C., estreando por volta de 430 a. C., já contava o nosso poeta com um vocabulário dos mais ricos, herdado da poesia satírica, em que realçam os nomes de Arquíloco e Hipônax, que já haviam introduzido na linguagem poética um grande número de vocábulos vu'gares e indecentes para designar as partes do corpo, as necessidades fisio'ógicas, além do linguajar característico de todos os frequientadores das bocas-de-lixo das cidades gregas. Além disso, já outros poetas cômicos anteriores como Crates e Epicarmo, ou contemporâneos como Cratino e Eúpolis usavam largamente em suas peças de têrmos chulos e vulgares, alguns herdados da tradição, outros por êles recém-inventados ou extraídos da linguagem do "bas-fond" de Atenas. Aliás o uso de palavrões e de cenas obscenas era essencial na comédia dêsse tempo, pois fazia parte da tradição que ela recebeu como herdeira dos festejantes do antigo "komós" (3)

Longe de ser o indicio de uma sociedade em decadência ou de um protesto contra as classes dominantes, a presença dos palavrões e das cenas escabrosas era um aspecto tradicional, profundamente impregnado de sentimentos religiosos. O palavrão, as cenas torpes correspond ${ }^{\circ} \mathrm{m}$ à satisfaç̃̃o de um apetite vital, da fruição de todos os gôzos da vida, o que cabia muito bem à missão de devotos de Dionisio como eram os poetas cômicos. Não havia malícia ou hipocrisia: o que se nota é o despudor franco e natural, além dos padrões da moral ou da decência. Um crítico francês recente, ao estabelecer um parale'o entre a obscenidade de Aristófanes e a pornografia moderna, aponta muito bem o contraste entre êsse obsceno que é normal, porque nasce naturalmente e "cette impudicité qui est malsaine parce qu'elle est nécessairement seconde, élaborée, engluée de littérature et de mora'e dans le défi même qu'elle leur porte. Notre obscenité

(3) - Não nos deteremos na discussão dêssss aspectos históricos, porque isso nos levaria à discussão da própria origem da comédia ática. 
est cynique quand elle s'étale, hypocrite quand elle se voile. Ma's celle d'Aristophane n'est jamais cynique, ni hypocrite,, ni "osée", elle est aussi normale que le coq sur la poule. L'obscenité moderne travaille sur l'écorché, ou dans le deshabillé; elle est malsaine. Aristophane est tout nu, comme un enfant et comme un animal. Il est sain" (4)

Ao contrário do que se tem afirmado geralmente, o palavrão em Aristófanes raramente é gratuito: ou brota espontâneamente como algo já esperado e que vem a calhar em determinadas circunstâncias ou então surge de surprêsa, de maneira totalmente inesperada. E é aí que está a sua fôrça: graças ao prazer de uma expectativa satisfeita ou ao contraste do inesperado, o palavrão é capaz de provocar o efeito desejado, temperando, condimentando o estilo cômico. Bem dosado, o palavrão dá gôsto e realce ao môlho, usado às mãos-cheias, açaba afastando da festa o comensal, saturado, quando não vítima de irrefreável alergia (5)

Todavia, não são os palavrões o maior obstáculo ao tradutor; sempre é possível encontrar correspondência, aproximações, pois que palavrões existem em tôdas as línguas, desde que o mundo é mundo; aliás, os valôres por êles visados quase sempre são os mesmos.

Muito maiores são as dificuldades encontradas na adaptação e tradução de palavras compostas, um dos recursos mais expressivos da língua grega, verdadeira surprêsa para quem fa'a o português, relativamente pobre em composição vocabular (6)

Os nomes compostos são de uso geral em grego, tanto em poesia como na prosa, em todos os níveis. Todavia eram favoritos dos poetas, e isso por vários motivos: a) pela possibilidade de expressão condensada, mais breve, tão necessária na linguagem poética, pelas próprias imposições da métrica; b) pela impressão de se preferir sugerir a estabelecer limites rígidos; c) pela possibilidade de expressar

(4) - Debedour V. H. Aristophane, Paris, Du Seuil, 1962 pg. 21. Aliás essa "directness" no trato de qualquer assunto é uma caractelística da arte grega, em qualquer de suas manifestações. Achamos oportuna essa digressão sôbre a licenciosidade no teatro de Aristófanes, em virtude da importância que se tem dado ao seu exame, nas discussões pró ou contra a legitimidade dos palavrōes em nosso teatro contemporâneo.

(5) - A título de curiosidade, gostaríamos de lembrar que nas "Nuvens", p. ex., num total de $1.500 \mathrm{vv}$ (mais ou menos 6.000 vocábulos) os palavrões não ultrapassam a casa dos 50 , menos de $1 \%$ !

(6) - A mesma deficiência já se notava no latim. E' digna de realce a habilidade de Plauto que foi realmente genial nos seus achados, ainda que se visse obrigado, muitas vêzes, a recorrer a elementos gregos para fo mação de seus compostos, que, assim, perdiam tôda a sua transparência para o espectador comum, não afeito à língua grega. 
conceitos novos, com uma certa nota de raridade, de afastamento da língua cotidiana (7)

Era fatal, portanto, que os compostos sobressaíssem como elementos de primeira grandeza no estilo de Aristófanes. E o poeta é dotado de uma capacidade verdadeiramente inesgotável de inventar novos compostos, quer adaptando-os a partir da troca ou substituição dos elementos componentes, quer empregando-os em situações inesperadas, ou então criando-os inteiramente novos. Que fazer dessas centenas de compostos, os "dipla onomata"? Inventar monstrengos que correspondam ao grego, mas que nada significam em nossa língua? Usar de perífrases que vão encompridar as frases, acabando por destruir o cômico? (8).

A expressividade dos compostos já sobressai na própria escolha dos nomes das personagens. Assim, por exemp'o, nos Acarnenses, o camponês pacifista que resolve de.ender a causa justa, procurando um Tratado de Paz com os lacedemônios é Dikaiopolis, "a Justa-Cidade"; se traduzimos por Diceópolis, teremos um nome estranho, inteiramente "opaco" para o leitor moderno. Se procurarmos uma forma aproximada como Justino, por exemplo, estaremos mantendo apenas um dos elementos - a idéia da justiça - mas estaremos desprezando o aspecto social dessa busca, pois o cidadão procura o tratado não apenas para si, mas para a Cidade. Nas Aves, o cidadão que procura um mundo nôvo, menos conturbado, é Evélpides - "o Boaesperança"; seu companheiro já é Pistetero, "o Fiel-Amigo", que talvez pudéssemos adaptar para Fidelino! Na Lisistrata, a mulher subversiva que resolve recorrer à greve sexual como único meio de acabar com a guerra, é a própria Lisistrata, cujo nome significa a "Solvente dos Exércitos", que talvez seria possível adaptar para "Desarmadora" ou "Soluguerra" No entanto, sempre estaremos muito longe da riqueza expressiva dos originais gregos, que desde as primeiras cenas já marcam com um timbre indelével o papel a ser desempenhado pelos personagens (9).

Aristófanes muitas vêzes forjava novos compostos a partir de outros já tradicionais na língua; recorria então ou à substituição de um dos elementos ou à inversão dos têrmos componentes. Tal é o caso,

(7) - Veja-se a propósito: Costa Ramalho A. - Dipla Onomata no Estilo de Aristófanes - supl. Rev. Humanitas, Coimbra, 1952.

(8) - Não é de se desprezar o fato de que, em se tratando de peças de teatro, o tempo é de suma importância: cada minuto a mais vai pesar na duração do espetáculo, criando problemas para a encenação.

(9) - Só os nomes próprios forjados por Aristófanes mereceriam um estudo à parte. Lembremos ainda, entre outros, Filocleon. e Blelycleon nas Vespas; Estrepsiades e Fidipides, nas Nuvens. 
por exemplo. de epíteto Brontesikeraunoi (10). "troverrelampejantes", cunhado para as Nuvens na peça homônima e que sugere imediatamente a nova era, em que s?̃o as Nuvens que mandam nas chuvas, em lugar do Zeus keraunós, terpikeraunós, que sempre aparecia depois de "ter trovejado", brontesas, portanto, conhecido como "senhor do raio e do trovão" já desde a poesia épica. E é interessante que o próprio Aristófanes, numa outra peça escrita pouco depois, A Paz, forja para o mesmo Zeus o epíteto keraunobrontés, com os mesmos elementos invertidos. E assim poderíamos apontar exemplos às dezenas .

Outras vêzes, são palavras inteiramente novas como o phrontisterion, "o pensatório", casa de Sócrates e seus discípulos os merimnophrontistai, "pensadores meditabundos, cheios de preocupações", que poderíamos adaptar para algo como cogito-pensadores, medito-pensadores. Ou ainda na mesma peça, (11) o vocábulo hàbi'mente cunhado que retrata a vaidade dos sofistas e poetas líricos da época, excessivamente preocupados com enfeites e atavios: são êles sphragidonychargokometai, "preguiçosos que só cuidam de cabelos, unhas e anéis de sinetes", ou melhor, ungueanelados-vadiocabeludos, para o que necessitamos de dois vocábulos compostos de dois elementos cada um. E, se os citaristas merecem essa crítica, por sua vez os sofistas e filósofos também são charlatastrônomos (meteorophenakai) (12)

Que dizer então daquele monstruoso vocábulo de mais de setenta e cinco sílabas em que o arauto do nôvo Estado comunitário promete aos cidadãos um menu pantagruélico, para depois, afinal, oferecer lhes uma tigelinha de sopa? (13).

Já em outro campo, o poeta recorre freqüentemente aos neologismos e co'oquialismos, reproduzindo a algaravia dos estrangeiros que perambulavam pela ágora de Atenas ou então o coaxar das rãs e os cantos dos pássaros. E' dos mais interessantes o efeito cômico provocado pelo refrão que as Rãs repetem sem cessar, como resposta aos versos de Dionisio:

\section{Brekekekex koax koax.}

E, à fôrça de insistir, acabam por conseguir a adesão do próprio deus, que incorpora o "ritornello" ao seu vocabulário, passando

(10) - Nuvens, v. 265.

(11) - Id. v. $94 ; 101$.

(12) - Id. v. 332, 333 .

(13) - Assembléia, v. 1168 ss. 
a iniciar tôdas as frases com o mesmo coaxado, justamente no momento em que os batráquios pareciam ter-se esquecido dêle! Não é um dos mais eloqüentes processos de criação cômica êsse que se realiza pelo automatismo, quando alguém é impelido a fazer ou a dizer o que não quer (ou não deve) pela fôrça persuasiva de uma teimosia que se repete?

Herdeiro de uma tradição de poesia cômica que já contava aproximadamente um século de vida, Aristófanes recebeu também como um dos elementos mais característicos do genêro cômico o hábito das enumerações, listas de vocábulos que se justapunham para serem recitados quase sempre de uma só vez, até que o interlocutor engasgasse ou perdesse o fôlego (14)

Desprezado e criticado pela tradição literária clássica, êsse recurso nos parece dos mais expressivos, justamente pela fôrça cumulativa que adquire a justaposição de têrmos às vêzes até incongruentes. Leo Spitzer, em seus Ensaios sôbre Lingüística e História Literária (15), procura atrair nossa atenção para a expressividade das enumerações no estilo de Rabelais, e para isso nos aponta tôda a série de adjetivos escolhidos para caracterizar os odiosos e odiados sofistas reacionários e hipócritas da Sorbonne. Ao ler essa passagem, não podemos deixar de lembrar-nos das enumerações de Aristófanes, notadamente aquela em que se acumulam adjetivos, verbos, substantivos, cada qual acrescentando algo mais à caricatura dos mestres de chicana, a quem o poeta odiava tanto. Nas Nuvens o velho Estrepsíades, endividado, entrega-se de corpo e alma aos mestres de retórica, que poderiam salvá-lo da bancarrota e, num momento de heróica resignação, o protagonista devia recitar de um só fôlego o seguinte monólogo: (16)

\author{
Este corpo que é meu eu lhes entrego \\ para apanhar ficar faminto e sedento \\ sujo enregelado sêco esfolado \\ se é que posso não pagar o que devo \\ e parecer diante do mundo \\ atrevido linguarudo ousado intrometido \\ velhaco grudador de mentiras
}

(14 - Esse processo já encontrado nos fragmentos de Epicarmo (poeta cômico de Mégara Hibléia da Sicília, inícios séc. V), segundo nos parece, associa ao automatismo a paródia de textos de poesia épica em que eram comuns as enumcraçōes, mormente nas genealogias.

(15) - Lingüistica e História Literária - Ed. Gredos, Madrid, $2^{\text {a }}$ ed. 1968, pág. 28 e ss.

(16) - Nuvens, v. 440 e ss. 


\begin{abstract}
paroleiro rábula super-escovado pedestal de leis charlatão raposa chicanista falador macio viscoso fanfarrão esculachado canalha chato arrevesado e fila-bóias...
\end{abstract}

E a mesma raiva transparece nas entrelinhas daquele final de discurso em que o cidadão Justino (Dikaiopolis) enumera tôda a movimentação, o bulício e as confusões dos preparativos duma campanha militar (17)

E a cidade estava cheia

"do tumulto dos soldados, gritaria para escolher o capitão, pagamento de soldos, efígies douradas de Atena, barulho nos armazéns, trigo racionado, odies, cravelhas de remos, compradores de jarras, alhos, azeitonas, cebolas em malhas, coroas, sardinhas, tocadores de flautas, olhos pisados!

No arsenal a mesma confusão: pás de remos, cravelhas pregadas, $r \in \operatorname{mos}$ encaixados, ruídos de flautas, patrões de barcos, pífaros e assobios!"

Gritaria, confusão e brigas, gastos inúteis, a sanha dos aproveitadores e até a presença das meretrizes nas vielas do pôrto, tudo é sugerido ou aparece de cambulhada nesse painel cheio de vida e côr.

Aristófanes também recorre com freqüência ao contraste que surge da inserção de vocábulos poéticos num diálogo banal, ou, ao contrário, da introdução de palavras triviais e até chulas em passagens de estilo elevado, que parodiam ou procuram imitar momentos de alta inspiração poética ou de profunda elocubração filosófica: do contraste e do inesperado nasce o cômico, ainda mais acentuado pela degradação dos valores (18) E é nessa mesma escala interpretativa que devemos estudar os pastichos e paródias, além do largo emprêgo do linguajar técnico, dos vários jargões profissionais, que o poeta consegue captar com uma habilidade quase inacreditável: reproduzindo em situações inesperadas êsses tiques e "gírias" profissionais, êle os submete a um processo degradativo, e com isso cria o ridículo.

(17) - Acarnenses, vv. 545-554.

(18) - Segundo a moderna interpretação axiológica do Riso "tôdas as pilhérias se relacionam com os valôres e tôdas procuram degradá-los" Cf. Stctrn A. - Filosofia de la Risa y del Planto trad. espanh., B. Aires, Iman, 1950, Cap. X. 
Já disse Henri Bergson que quase tôda palavra tem, por assim dizer, dois sentidos: um físico e um moral, conforme a tomemos no sentido próprio ou no sentido figurado. Concentrando a atenção no aspecto material de uma metáfora, por exemplo, provocamos o riso justamente por êsse processo de coisificação que lhe impomos. Aliás, êsse processo que muitas vêzes conduz à distração, ao quiproquó, ao jôgo de palavras, pode também ser explicado pelo fato de o sentido primeiro do vocábulo conservar-se no nível do pensamento eubconsciente. Tal o caso daquela típica anedota de judeus, relatada por Freud numa de suas obras:

"No saguão de um Hotel, um turista judeu encontra-se com um amigo e lhe pergunta:

- Você já tomou banho?

E o outro responde:

- Por que, está faltando algum?"

Tôda a pilhéria resulta do sentido do verbo tomar ("apanhar", "tirar") que, inconscientemente ocorreu ao interrogado.

Ora, são inúmeras as situações semelhantes que podemos apontar no teatro de Aristófanes. Bastaria recordar a cena em que o velho Estrepsíades, campônes avarento e materialista, vai procurar Sócrates para instruir-se. Pergunta-lhe o mestre:

Soc.: "Que você desejaria aprender primeiro, as medidas, os versos ou os ritmos?

Estr.: As medidas, é claro.! Pois se há uns dias fui tapeado por um mercador em duas medidas de farinha...

Soc.: Não é nada disso. Mas o que você prefere, a medida de três ou de quatro?

Estr.: Ora, para mim não há nada melhor do que o quartilho" (19).

Enquanto um raciocina no plano da retórica, o outro tem em mente apenas coisas materiais, e é dessa coisificação da palavra metron, medida, que nasce o quiproquó, o cômico.

Muitos outros ainda são os recursos de que se utiliza Aristófanes, alguns mais grosseiros, menos ricos de expressividade, como os trocadilhos, os "calembourgs", que aliás dificilmente suportam uma tradução adequada, e outros mais sutis, evidenciando uma riqueza bem maior, como as "pilhéria pelo inesperado" (par'hyponoian), em que o elemento cômico fundamental é o contraste estabelecido por uma palavra completamente fora de cogitação, no contexto, e atirada à queima roupa.

(19) - Nuvens, v. 637-644 
O velho Estrepsíades vira-se na cama, sem poder dormir, atribulado com as dívidas que não pode pagar $O$ filho "play-boy" e causador de tudo resmunga:

"Puxa, papai, por que você se agita e se mexe a noite inteira?" E o velho responde:

"Morde-me... um meirinho... lá do fundo das cobertas..." (20.

E para concluir, reunindo uma série de exemplos bem característicos dessa linguagem cômica, recorramos aos Cavaleiros, à cena em que os escravos Nícias e Demóstenes, personificando dois prestigiosos políticos e generais da época, se queixam do patrão Demos (o povo ateniense), inteiramente sucumbido diante das lisonjas de um escravo nôvo, demagogo sem escrúpulos, que outro não é senão o político Cleão, orador irascível, demagogo violento, curtidor de couros por profissão e líder dos democratas exaltados, que se achavam no poder (21)

.. Nós temos um patrão

grosseiro e agressivo, papa-votos ranzinza,

Populino Comício, velhote birrento

e meio surdo. No fim do mês passado,

êle comprou um escravo, um curtidor das Arábias,

fulano mais ladino e caluniador!

Esse dai, depois que aprendeu as manias do velho,

o Curtiárabe, se atirou aos pés do patrão

e toca a alisar, bajular, adular e iludir...

... com aparinhas de couro ... E vai dizendo:

"Populino, você já julgou uma causa! vá descansar!

Vá tomar um banho! Coma essa papinha, engula, devore, tome um aumento de salário!

Quer que eu lhe sirva o jantar?" Rápido

rouba o prato que um de nós preparou pro patrão

e vai correndo lhe dar de presente...

Mantém-nos à distância, não deixa nenhum outro cuidar do patrão.

De pé, ao seu lado, com umas tiras de couro na mão, durante o jantar... espanta os oradores!

(20) - Nuvens, vv. $35-37$.

(21) - Cavaleiros, vv. 40 e ss. 
E, ainda mais, sabe tirar sortes!

E o velho delira, como um médium em transe!

Então, quando êle vê o velho totalmente abobado, começa 0 joguinho: contra $\circ$ pessoal da casa inventa calúnias, e nós é que apanhamos!..."

Não é preciso que conheçamos a fundo a história de Atenas e do político Cleão, nos anos de 425-421 a.C. Ainda que ignoremos os sucessos de Pilos e Esfactéria, em que o hábil líder popular empalmou as vitórias de seus generais Nícias e Demóstenes, não podemos deixar de rir, pois a fôrça expressiva da linguagem nos apresenta um retrato fiel de um fato que sempre se repete: o pobre e tolo povo, enganado e boquiaberto diante das mentiras e promessas de um demagogo qualquer.

Cremos, então, que, apesar de todos os percalços, muita coisa ainda pode salvar-se do naufrágio: Aristófanes é capaz de fazer-nos rir. E é justamente essa a sua grandeza, pois, embora destruído e abalado pelos azares do tempo, ainda consegue chegar até nós, com vida, graça e elegância. 